\title{
Pengaruh Literasi Ekonomi, Pengelolaan Uang Saku, Dan Kontrol Diri Terhadap Rasionalitas Perilaku Konsumsi Mahasiswa
}

\author{
Yultiana Marsela \\ e-mail: marselayulti.com \\ Rusno \\ Walipah
}

(Program Studi Pendidikan Ekonomi, Fakultas Ekonomika dan Bisnis, Universitas Kanjuruhan, Malang)

\begin{abstract}
ABSTRAK: Penelitian memiliki tujuan yaitu agar memahami pengaruh literasi ekonomi, pengelolaan uang saku, dan kontrol diri terhadap rasionalitas perilaku konsumsi Mahasiswa Pendidikan Ekonomi Universitas Kanjuruhan Malang. Subjek dalam penelitian ini adalah Pendidikan Ekonomi Universitas Kanjuruhan Malang berjumlah 87 mahasiswa. Alat pengumpulan data dalam penelitian ini berupa angket dan dokumentasi. Hasil penelitian menunjukan bahwa ditemukan dampak positif dan signifikan dari literasi ekonomi, pengelolaan uang saku dan kontrol diri terhadap rasionalitas perilaku konsumsi mahasiswa pendidikan ekonomi Universitas Kanjuruhan Malang.
\end{abstract}

Kata kunci : literasi ekonomi, pengelolaan uang saku, kontrol diri, rasionalitas perilaku konsumsi

Abstrack: The aim of this research is to understand the effect of economic literacy, pocket money management, and self-control on the rationality of consumption behavior of Economics Education Student of Universitas Kanjuruhan Malang. The subjects in this study were Kanjuruhan University Malang Economic Education totaling 87 students. Data collection tools in this study were in the form of questionnaires and documentation. The results showed that found positive and significant impact of economic literacy, pocket money management and self control on the rationality of consumption behavior of Economics Education Student of Universitas Kanjuruhan Malang.

Keywords : economic literacy, pocket money management, self-control, rationality of consumption behavior.

\section{PENDAHULUAN}

Manusia dalam kehidupan nyata tidak bisa terlepas dari kegiatan ekonomi untuk memenuhi segala kebutuhan hidup yang berbagai macam. Pada dasarnya untuk memenuhi semua kebutuhan hidup, kita tidak bisa menghindari dari permasalahan Kecenderungan manusia untuk melakukan kegiatan konsumsi tidak ada batasnya Manusia lebih mementingkan faktor emosi dari pada tindakan rasional. Robert F. Duvall, Presiden dan CEO Dewan Nasional Pendidikan Ekonomi (NCEE) dalam Neti Budiwati (2014:19) menyampaikan bahwa literasi ekonomi yaitu kemampuan yang penting, sama manfaatnya dengan membaca literasi. Memiliki ilmu dasar ekonomi mahasiswa mampu memanajemen keuangannya secara maksimal. Mahasiswa wajib bisa menekan pengelolaan uangnya untuk membedakan apa yang menjadi kebutuhan dan juga apa yang menjadi keinginan. 
Pengaruh Literasi Ekonomi, Pengelolaan uang saku, Dan Kontrol Diri Terhadap rasionalitas Perilaku konsumsi Mahasiswa

Namun, pada kenyataanya masih banyak mahasiswa pendidikan ekonomi yang belum mengetahui. Alam (2013:46) dalam ilmu ekonomi, "konsumsi adalah suatu kegiatan yang bertujuan untuk mengurangi atau menghabiskan faedah suatu benda (barang dan jasa) dalam rangka memenuhi kebutuhan".

Aspek yang mempengaruhi perilaku konsumsi, diantaranya yaitu ada aspek yang berasal dari ekonomi seperti penghasilan, barang, jasa, dan tingkat pendidikan. Sementara faktor non ekonomi seperti faktor, slera, jumlah keluarga, mode, lingkungan dan budaya. Faktor tersebut merupakan faktor yang mempengaruhi konsumen dalam perilaku membeli dan dalam melakukan keputusan pembelian suatu barang. Dalam hal ini dipengaruhi juga oleh uang saku yang diterima oleh mahasiswa. Mahasiswa yang memiliki pengetahuan dalam mengelola uang, akan mampu mengelola perilaku konsumsinya, diperlakukan pengetahuan bagaimana teknik dan mengelola keuangan tersebut menjadi hal yang tidak dapat diabaikan lagi seperti pada waktu sebelumnya. Pengelolaan uang saku yang diterima mahasiswa tidak digunakan secara rasional. Sebagaimana Nitisusastro (2012) menyampaikan bahwa perilaku konsumsi merupakan tindakan yang didasarkan pada pertimbangan yang rasional. Namun pada kenyataanya peneliti melihat cara mengelola uang saku yang diterima oleh mahasiswa berbanding terbalik dengan rasionalitas perilaku konsumsi.

Pengelolaan Uang saku yang benar dapat dilakukan sejak awal, hal ini bertujuan untuk mengatasi hal-hal yang terjadi di masa depan. Faktor yang mempengaruhi perilaku konsumsi pembelian merupakan temperamen seseorang. Pada umumnya konsumsi rutin merupakan segala biaya untuk membeli barang dan jasa-jasa yang dilakukan secara terus menerus dikeluarkan, sementara kondisi tidak rutin yaitu setiap tambahan yang tidak terduga. Namun dari pendapatan yang ada masih banyak mahasiswa pendidikan ekonomi belum bisa mengontrol diri dalam memanajemenkan keuangan yang didapatkan dengan menggunakannya secara rasional. Kontrol diri yang diutarakan oleh Averill (dalam Ghufron dan Risnawita, 2011) adalah keahlian seseorang untuk bisa mengendalikan informasi baik penting ataupun tidak, dalam kemahiran individu untuk memilih suatu langklah yang pasti.

Kontrol diri yaitu kemampuan seseorang untuk mengendalikan dirinya sendiri agar dalam keadaan sadar agar berperilaku yang tidak akan merugikan orang lain. Namun pada mahasiswa pendidikan ekonomi masih ada yang belum bisa mengontrol diri dalam berkonsumsi, sehingga banyak mahasiswa yang cendrung berperilaku secara irasional. Kontrol diri sangat berguna agar bisa bergaul dengan orang lain dan untuk mencapai destinasi pribadi. Dalam hal ini individu diupayakan untuk dapat memperoleh keinginan yang maksimal serta untuk mengaktualkan hidupnya. Masing-masing individu mempunyai konsep diri, baik itu yang bersifat positif maupun bersifat negatif hanya kadarnya yang berbeda-beda.

\section{TINJAUAN PUSTAKA}

Wahyudi (2013:30) mendefinisikan arti Perilaku konsumsi merupakan tindakan individu tidak lagi berdasarkan pertimbangan yang rasional, hasrat yang besar untuk memiliki benda-benda mewah untuk memenuhi segala kesenangan semata-mata. Konsumsi dalam hal ini tidak lagi berdasarkan kebutuhan, namun berkonsumsi dilakukan karena keinginan. Menurut Nitisusastro (2012) mengemukakan rasional perilaku konsumsi adalah perilaku yang didasari atas pertimbangan bahwa suatu barang atau jasa dibeli dan diperhitungan secara rasional. Menurut Kotler (dalam 
Pengaruh Literasi Ekonomi, Pengelolaan uang saku, Dan Kontrol Diri Terhadap rasionalitas Perilaku konsumsi Mahasiswa

Gumanti,Desty dkk 2012: 232) dipengaruhi oleh beberapa faktor yaitu : 1) Faktor budaya. Faktor budaya antara lain: (1) Peran budaya, (2) Sub budaya, (3) Kelas sosial pembeli. 2) Faktor sosial. Faktor-faktor sosial antara lain: (1) Kelompok acuan, (2) Keluarga, (3) Peran dan status. (3) Fktor Pribadi. Variabel-variabel yang termasuk dalam faktor individu yaitu: (1) Usia dan tahap siklus hidup Sepanjang hidup, (2) Pekerjaan dan lingk-ungan

ekonomi, (3) Gaya hidup. (4) Kepribadian dan konsep diri.

Sebagai mahluk sosial pasti melalukan kegiatan konsumsi, namun kegiatan konsumisi itu sebenarnya harus didasari dengan literasi ekonomi. hal ini bertujuan agar terhindar dari perilaku konsumsi secara irasional. While Wulandari (in Neti Budiwati 2010) said that "economic literacy is actually a life skill that every student must possess.However the students lack chances to experience, consequently the knowledge obtained cannot be implemented. Economics literacy includes the individual ability and awareness about wha is, why should, and how to be a wise consumer, smart producer, saver and cinvestor, productive worker and responsible citizen. Perilaku rasionalitas konsumsi mahasiswa dipengaruhi oleh uang saku, dimana jika mahasiswa mengelola uang sakunya dengan baik maka tingkat rasional dalam berkonsumsi ikut baik pula. Uang saku merupakan pendapatan diterima oleh mahasiswa yang berasal dari orang tua dengan perencanaan uang tersebut dapat digunakan membeli jajanan, biaya transportasi, dan kebutuhan lainnya. Biasanya mahasiswa menerima uang saku pada setiap bulan, setiap minggu, ataupun setiap hari. Menurut Basrowi dan Juariyah (2010) Uang saku yaitu uang yang diterima, contoh dalam satu bulan untuk memenuhi kebutuhan pangan dan non pangan. Uang saku juga dibutuhkan untuk keberhasilan dalam proses belajar. Sumber uang saku contohnya berasal dari dana bidikmisi (bantuan biaya hidup), uang dari orang tua atau keluarga, pekerjaan sampingan dan lain sebagainya. Setiap mahasiswa diberi kebebasan dan tanggung jawab dalam memanajemen uang saku tersebut. Pengelolaan uang dilakukan sebagai tanggung jawab masingmasing individu dalam kehidupan sehari-hari untuk memenuhi kebutuhan sehari-hari.

Menurut Ghufron (2014:21) kontrol diri yaitu suatu kecakapan individu dalam rentanan melihat situasi diri dan lingkungannya. Selanjutnya, juga kemampuan untuk mengendali dan mengelola faktor-faktor perilaku sesuai dengan situasi dan kondisi untuk menampilkan diri dalam melakuka sosialisasi kemampuan. Sementara Menurut Syamsul (2010: 107) kontrol diri yaitu ke mampuan individu untuk mengendalikan dorongan, baik dari dalam maupun luar diri individu. Berdasarkan pendapat diatas atas, kontrol diri dapat diartikan sebagai suatu aktivitas pengen dalian tingkah laku. Kontrol diri berkaitan dengan bagaimana individu mengendalikan emosi serta dorongan-dorongan dari dalam dirinya..

Menurut Block dan Block (dalam Ghufron, 2014:31) mengemukakan tiga jenis kontrol, yaitu: 1) Over control, 2) Appropriate control,3) Under control. Ada dua factor kontrol diri yaitu factor internal dan eksternal.

\section{METODE}

Metode yang digunakan dalam penelitian ini adalah metode kuantitatif. Sesuai dengan masalah dan tujuan penelitian, maka penelitian ini merupakan penelitian deskriptif dengan menggunakan pendekatan kuantitatif. Menurut Sugiyono (2012:13) penelitian deskriptif merupakan 
Pengaruh Literasi Ekonomi, Pengelolaan uang saku, Dan Kontrol Diri Terhadap rasionalitas Perilaku konsumsi Mahasiswa

penelitian yang dilakukan untuk mengenal nilai variabel mandiri baik satu variabel atau lebih (independen) tanpa membuat perbandingan, atau menghubungkan dengan variabel yang lain.

Populasi dalam penelitian ini adalah Mahasiswa Pendidikan Ekonomi Universitas Kanjuruhan Malang 2016-2019 yang berjumlah 87 mahasiswa. Penelitian ini merupakan penelitian populasi karena jumlah populasinya yang relatif sedikit atau populasinya kurang dari 100 responden. Jadi pada penelitian ini peneliti mengambil $100 \%$ jumlah populasi adalah mahasiswa pendidikan ekonomi angkatan 2016-2019 sejumlah 87 orang responden. Oleh karena itu teknik yang digunakan pada penelitian ini yaitu menggunakan teknik sampel jenuh. Teknik sampel jenuh merupakan teknik penentuan seluruh populasi digunakan sebagai sampel. Data pada penelitian ini dikumpulkan menggunakn angket. Angket digunakan untuk mengumpulkan data dari rasionalitas Perilaku Konsumtif, pengelolaan uang saku dan kontrol diri. Angket menggunakan skala likert dengan pernyataan berjumlah 42 item.

\section{HASIL DAN PEMBAHASAN}

Berdasarkan hasil penelitian, dapat dideskripsikan gambaran masing-masing variabel di lapangan untuk literasi ekonomi dari sampel mahasiswa Pendidikan Ekonomi Universitas Kanjuruhan Malang nilai dari setiap alternatif jawaban pada kuesioner tentang literasi ekonomi $\left(X_{1}\right)$ dengan jumlah 10 pernyataan 40,35\% responden yang menjawab selalu, 38,96\% jawab sering, 16,3\% jawab kadang-kadang, 3,78\% dan 0,057\% yang menjawab tidak pernah. Hal ini menunjukan Mahasiswa yang menjawab selalu dan sering sebesar 79,31\% yang berarti mahasiswa pendidikan Ekonomi Universitas Kanjuruhan Malang memiliki literasi ekonomi yang sangat baik.

Gambaran dari variabel pengelolaan uang $\left(X_{2}\right)$ dengan jumlah 8 pernyataan $14 \%$ responden yang menjawab selalu, 31,4\% jawab sering, 32\% jawab kadang-kadang, 16\% jawab pernah, dan 7\% jawab tidak pernah. Hal ini menunjukan Mahasiswa yang menjawab selalu dan sering sebesar 45,4\% yang berarti mahasiswa pendidikan Ekonomi Universitas Kanjuruhan Malang memiliki pengelolaan uang saku yang cukup tinggi.

Variabel kontrol diri $\left(X_{3}\right)$ dengan jumlah 10 pernyataan $14 \%$ responden yang menjawab selalu, 29,4\% jawab sering, 33,12\% jawab kadang-kadang, 18,5\% jawab pernah, dan 5,05\% menjawab tidak pernah. Hal ini menunjukan Mahasiswa yang menjawab selalu dan sering sebesar $43,42 \%$ yang berarti mahasiswa pendidikan Ekonomi Universitas Kanjuruhan Malang memiliki kontrol diri yang cukup baik.

Kondisi rasionalitas perilaku konsumsi (Y) dengan jumlah 14 pernyataan 18,7\% responden yang menjawab selalu, 18,2\% menjawab sering, 22,5\% menjawab kadang-kadang, 20,5\% menjawab pernah, dan 20,02\% menjawab tidak pernah. Hal ini menunjukan individu yang menjawab selalu dan sering sebesar $36.9 \%$ yang berarti mahasiswa pendidikan Ekonomi Universitas Kanjuruhan Malang memiliki rasionalitas konsumsi yang rendah.

Berdasarkan Uji F digunakan untuk menguji hipotesis ke 4 atau $\left(\mathrm{H}_{\mathrm{I}}\right)$ yaitu diduga bahwa variabel $\mathrm{X}_{1}$ (literasi ekonomi), $\mathrm{X}_{2}$ (variabel pengelolaan uang saku), $\mathrm{X}_{3}$ (variabel kontrol diri), secara simultan berpengaruh terhadap variabel Y (rasionalitas perilaku konsumsi) dasar pengambilan keputusan untuk pengujian hipotesis yang diajukan adalah sebagai berikut: Jikan nilai $F_{\text {Hitung }}>$ $F_{t a b e l}$ dan nilai probabilitas $<0,05$ maka variabel bebas $(X)$ secara simultan memiliki pengaruh yang 
Pengaruh Literasi Ekonomi, Pengelolaan uang saku, Dan Kontrol Diri Terhadap rasionalitas Perilaku konsumsi Mahasiswa

signifikan terhadap variabel terikat (Y), Jika nilai $F_{\text {Hitung }<} F_{\text {tabel }}$ dan nilai probabilitas $>0,05$ maka variabel bebas $(X)$ secara simultan tidak memiliki pengaruh yang signifikan terhadap variabel terikat (Y). Hasil pengujian Uji F dapat dilihat pada Tabel sebagai berikut:

Tabel 1. Hasil Uji F

\begin{tabular}{|c|c|c|c|c|c|c|}
\hline \multicolumn{7}{|c|}{ ANOVA $^{\mathrm{a}}$} \\
\hline & & Sum of & & & & \\
\hline \multicolumn{2}{|r|}{ Model } & Squares & Df & Mean Square & $\mathrm{F}$ & Sig. \\
\hline \multirow[t]{3}{*}{1} & Regression & 272.946 & 3 & 90.982 & 9.925 & $.000^{\mathrm{b}}$ \\
\hline & Residual & 760.870 & 83 & 9.167 & & \\
\hline & Total & 1033.816 & 86 & & & \\
\hline
\end{tabular}

a. Dependen variabel : rasionalitas perilaku konsumsi

b. Predictors: (Constant), kontrol diri, pengelolaan uang saku, literasi ekonomi. Sumber: Data hasil pengolahan SPSS 22.00

Hasil tes ANOVA diperoleh nilai $F_{\text {Hitung }}>F_{\text {tabel }}$ dan nilai signifikan 0,000 $<0,05$ maka dapat diambil kesimpulannya terdapat pengaruh yang signifikan secara simultan literasi ekonomi pengelolaan uang saku dan kontrol diri terhadap rasionalitas perilaku konsumsi mahasiswa. Maka $\mathrm{H}_{\mathrm{o}}$ ditolak dan $\mathrm{H}_{\mathrm{I}}$ diterima

Berdasarkan data penelitian, dapat diperoleh regresi berganda dalam penelitian ini adalah sebagai berikut

Tabel 2. Hasil uji regresi linier berganda Coefficient $^{a}$

\begin{tabular}{|c|c|c|c|c|c|c|}
\hline \multicolumn{2}{|r|}{ Model } & \multicolumn{2}{|c|}{$\begin{array}{l}\text { Unstandardized } \\
\text { Coefficients }\end{array}$} & \multirow{2}{*}{$\begin{array}{c}\begin{array}{c}\text { Standardized } \\
\text { Coefficients }\end{array} \\
\text { Beta }\end{array}$} & \multirow[b]{3}{*}{$\mathbf{t}$} & \multirow[b]{3}{*}{ Sig. } \\
\hline \multirow[t]{6}{*}{1} & & B & Std. Error & & & \\
\hline & & & & & & \\
\hline & (Constant) & .382 & 7.730 & & .049 & .961 \\
\hline & Literasi Ekonomi & .409 & .136 & .288 & 3.013 & .003 \\
\hline & $\begin{array}{ll}\text { Pengelolaan } & \text { Uang } \\
\text { Saku } & \\
\end{array}$ & .526 & .178 & .278 & 2.951 & .004 \\
\hline & Kontrol Diri & .306 & .104 & .280 & 2.929 & .004 \\
\hline
\end{tabular}

a. Dependent Variabel: Rasionalitas Perilaku Konsumsi

Berdasarkan hasil analisis regresi berganda tersebut, diartikan terjadi dmpak yang positif antara variabel literasi ekonomi (X1), pengelolaan uang saku (X2), kontrol diri (X3), terhadap variabel rasionalitas perilaku konsumsi (Y).

Berdasarkan Uji t digunakan untuk menguji signifikan pengaruh masing-masing variabel independen yang terdiri dari literasi ekonomi, pengelolaan uang saku dan kontrol diri dengan variabel dependen yaitu rasionalitas perilaku konsumsi. Hasil uji pada penelitian ini dapat dilihat pada Tabel sebagai berikut 
Pengaruh Literasi Ekonomi, Pengelolaan uang saku, Dan Kontrol Diri Terhadap rasionalitas Perilaku konsumsi Mahasiswa

Tabel 3. Hasil Uji t

\begin{tabular}{lcccl}
\hline & Model & $\mathbf{t}$ & Sig. & Keterangan \\
\hline 1 & & & & \\
\cline { 2 - 5 } & (Constant) & .049 & .961 & \\
\hline Literasi Ekonomi & 3.013 & .003 & Signifikan \\
\hline $\begin{array}{c}\text { Pengelolaan Uang Saku } \\
\text { Kontrol Diri }\end{array}$ & 2.951 & .004 & Signifikan \\
\hline Kontrol Diri & 2.929 & .004 & Signifikan \\
\hline
\end{tabular}

Hipotesis penelitian kedua $\left(\mathrm{H}_{2}\right)$ adalah diduga ada pengaruh yang signifikan secara parsial literasi ekonomi terhadap rasionalitas perilaku konsumsi. Berdasarkan Tabel 4.7 menunjukan variabel literasi ekonomi memperoleh nilai $t$ sebesar 3.013, tingkat signifikan 0,003, karena nilai signifikan $\mathrm{t}<0,05$, maka variabel $\mathrm{X}_{1}$ (Literasi ekonomi) berpengaruh variabel $\mathrm{Y}$ (rasionalitas perilaku konsumsi). Dengan demikian $\mathrm{H}_{0}$ ditolak dan $\mathrm{H}_{2}$ diterima, berarti variabel literasi ekonomi berpengaruh signifikan secara parsial terhadap rasionalitas perilaku konsumsi mahasiswa.

Hipotesis penelitian ke tiga $\left(\mathrm{H}_{3}\right)$ adalah diduga ada pengaruh yang signifikan secara parsial pengelolaan uang saku tehadap rasionalitas perilaku konsumsi. Berdasarkan Tabel 4.7 menunjuukan bahwa variabel pengelolaan uang saku $\left(\mathrm{X}_{2}\right)$ memperoleh nilai $\mathrm{t}$ sebesar 2.951 dengan tingkat signifikan 0,004, karena taraf signifikan lebih kecil dari 0,05, maka variabel $\mathrm{X}_{2}$ berpengaruh terhadap variabel $\mathrm{Y}$ (rasionalitas perilaku konsumsi). Dengan demikian $\mathrm{H}_{0}$ ditolak dan $\mathrm{H}_{3}$ diterima, berarti variabel pengelolaan uang saku berpengaruh signifikan secara parsial terhadap rasionalitas perilaku konsumsi.

Hipotesis penelitian ke empat $\left(\mathrm{H}_{4}\right)$ adalah diduga ada pengaruh yang berarti secara parsial kontrol diri terhadap rasionalitas perilaku konsumsi. Berdasarkan Tabel 4.7 dapat diketahui bahwa variabel kontrol diri $\left(\mathrm{X}_{3}\right)$ memperoleh nilai $\mathrm{t}$ sebesar 2,929 dengan tingkat signifikan 0,004. Karena nilai signifikan $<0,05$ maka variabel kontrol diri $\left(\mathrm{X}_{3}\right)$ berpengaruh signifikan terhadap varibel $\mathrm{Y}$ (pengelolaan uang saku). Dengan demikian $\mathrm{H}_{0}$ ditolak dan $\mathrm{H}_{4}$ diterima, berarti variabel kontrol diri berpengaruh signifikan secara parsial terhadap rasionalitas perilaku konsumsi mahasiswa

\section{KESIMPULAN}

Berdasarkan hasil penelitian peneliti menyimpulkan terdapat pengaruh yang berarti secara simultan literasi ekonomi, pengelolaan uang saku, dan kontrol diri terhadap rasionalitas perilaku konsumsi Mahasiswa Pendidikan Ekonomi Universitas Kanjuruhan Malang. Nilai uji $F_{\text {hitung }}$ sebesar 9,925dengan signifikan 0,000 maka $H_{0}$ ditolak dan $H_{\alpha}$ diterima, yang berarti bahwa literasi ekonomi, pengelolaan uang saku, dan kontrol diri memiliki pengaruh secara simultan terhadap rasionalitas perilaku konsumsi. Terdapat pengaruh yang signifikan secara parsial literasi ekonomi terhadap rasionalitas perilaku konsumsi Mahasiswa Pendidikan Ekonomi Universitas 
Pengaruh Literasi Ekonomi, Pengelolaan uang saku, Dan Kontrol Diri Terhadap rasionalitas Perilaku konsumsi Mahasiswa

Kanjuruhan Malang. Hal ini dapat dilihat pada hasil penelitian terdapat sebagain besar mahasiswa memiliki tingkat literasi ekonomi yang sangat baik, sehingga Mahasiswa Pendidikan Ekonomi Universitas Kanjuruhan Malang cendrung pada berperilaku konsumsi yang sangat baik dan rasional.Terdapat pengaruh yang signifikan secara parsial pengelolaan uang saku terhadap rasionalitas perilaku konsumsi Mahasiswa Pendidikan Ekonomi Universitas Kanjuruhan Malang. Hal ini dapat dilihat pada hasil penelitian terdapat sebagain besar mahasiswa memiliki tingkat pengelolaan uang saku yang cukup baik, sehingga Mahasiswa Pendidikan Ekonomi Universitas Kanjuruhan Malang cendrung pada berkonsumsi yang baik dan rasional. Ada pengaruh yang signifikan secara parsial kontrol diri terhadap rasionalitas perilaku konsumsi Mahasiswa Pendidikan Ekonomi Universitas Kanjuruhan Malang. Hal ini dapat dilihat pada hasil penelitian terdapat sebagain besar mahasiswa memiliki tingkat kontrol diri yang cukup baik, sehingga Mahasiswa Pendidikan Ekonomi Universitas Kanjuruhan Malang cendrung pada berkonsumsi yang baik dan rasional.

\section{DAFTAR PUSTAKA}

Alam S, 2013. EkonomiUntuk SMA/MA Kelas X. Jakarta: Erlangga

Budiwati,Neti.(2010). Developing Economic Literacy-Based Learning Model (Study On Economic Studies In Public High Schools In Bandung City).journal

Budiwati, Neti. (2014). Disertasi : Analisis Literasi Ekonomi Dan Perilaku Konsumen. (Survey pada Guru SMA di Kota Bandung). Bandung : Universitas Pendidikan Indonesia.

Deliarnov. (2015). Perkembangan Pemikiran Ekonomi. Jakarta : Pt. Raja Grafindo Persada

Ghufron, M. N., \& Risnawita S, R. (2012). Teori-teori psikologi (cetakan ketiga). Jokjakarta: Ar-Ruzz Media.

Kotler. (2012). manajemen pemasarana: analisis, perencanaan, implementasi dan pengendalian jilid 1. Jakarta: Erlangga

Maharani, Rosida. 2018. Pengaruh Modernitas Dan Literasi Ekonomi Terhadap Perilaku Konsumsi Siswa Kelas Xi Iis Di Sma Negeri 1 Talun. Vol.6.No3

NCEE. 2018. “Economic Literacy Quiz.” https://www.councilforeconed.org/new information/econ omic-literacy-quiz/.

Neti Budiwati. (2014). Analisis Literasi Ekonomi dan Perilaku Konsumen. Disertasi. Bandung: Universitas Pendidikan Indonesia.

Nitisusastro, Rosida. 2012. Pengaruh Modernitas Dan Literasi Ekonomi Terhadap Perilaku Konsumsi Siswa Kelas XI Di SMA Negri 1 Talun .vol.6.No.3

Sina, Peter Garlans. 2012. "Analisis Literasi Ekonomi." Jurnal Economia 8(2): 135-43. https://journal.uny.ac.id/index.php/economia/article/view/1223

Sugiyono. (2012). Metode Penelitian Kuantitatif dan RED. Bandung : Alfabeta

Sugiyono. (2013). Statistika untuk Penelitian. Bandung: Alfabeta

Wahyudi. 2013. "Tinjauan tentang Perilaku Konsumtif Remaja Pengunjung Mall Samarinda Central Plaza. eJournal Sosiologi, Volume 1, Nomor 4, 201326 -36.http://ejournal.sos.fisipunmul.ac.id/site/wp content/uploads/2013/11/ Jurnl\%20w ahyudi\%20PDF\%20\%2811-07-13-07- 45-39\%29.pdf.

Diakses pada tanggal 5 Desember 2014 